Revista Brasileira de

Engenharia Agrícola e Ambiental

v.16, n.4, p.329-336, 2012

Campina Grande, PB, UAEA/UFCG - http://www.agriambi.com.br

agriambi

Protocolo 145.09 - 01/10/2009 • Aprovado em 30/01/2012

\title{
Q ualidade física de um Latossolo Vermelho em recuperação há dezessete anos
}

\author{
Carolina S. B. Bonini ${ }^{1} \&$ Marlene C. Alves ${ }^{1}$
}

\section{RESU MO}

Com o objetivo de avaliar a qualidade física de um Latossolo Vermelho em recuperação há 17 anos utilizando-se adubos verdes, gesso e pastagem, foram estudados a densidade do solo e resistência a penetração, como indicadores de sua recuperação. 0 delineamento experimental foi inteiramente casualizado com nove tratamentos e quatro repetições. Os tratamentos foram: Solo mobilizado; mucunapreta (MP); guandu (G) até 1994, após substituído por feijão-de-porco (FP); calcário + M P; Calcário + G até 1994, após substituído por FP; calcário + gesso + MP; calcário + gesso + G até 1994, após substituído por FP; os tratamentos foram instalados em 1992 e permaneceram por sete anos e em 1999 implantou-se a Brachiaria decumbens; também foram utilizadas duas testemunhas para comparação (vegetação nativa do cerrado e solo exposto). Foram avaliadas densidade do solo, resistência do solo à penetração e umidade do solo. O s resultados foram analisados efetuando-se a análise de variância e teste de Tukey a $5 \%$ de probabilidade. 0 s tratamentos de recuperação do solo estão sendo eficientes na melhoria da sua qualidade e o tratamento com guandu/feijão-de-porco, calcário e gesso, obteve condições físicas semelhantes às do solo de cerrado.

Palavras-chave: área de empréstimo, degradação do solo, adubação verde; matéria orgânica

\section{Physical quality of oxisol under reclamation for 17 years}

\begin{abstract}
AB STRACT
The bulk density and resistance to penetration as indicators of recovery were studied with the objective to investigate the physical quality of a Red Latosol (0xisol) under restoration for 17 years using green manures, soil correction, gypsum and pasture. The experimental design was a completely randomized with nine treatments and four replications. The treatments were: control (tilled soil without crop); Stizolobium aterrium; Cajanus cajan until 1994 and then substituted by Canavalia ensiformis; lime+ S. aterrimum; lime+ $C$. cajan until 1994 and then substituted by $C$. ensiformis; lime+ gypsum + S. aterrimum; lime+ gypsum $+C$. cajan until 1994 and then substituted by $C$. ensiformis, the treatments were installed in 1992 and remained for seven years, in 1999 Brachiaria decumbens was planted; two other controls (native vegetation and exposed soil) were also used to compare. Bulk density, resistance to penetration and soil moisture were evaluated. The results were analyzed performing analysis of variance and Tukey test at probability of $5 \%$ to compare means. The treatments of reclamation are improving the physical qualities of soil and the results of treatment with $C$. cajan/C. ensiformis, lime and gypsum attained physical conditioning similar to soil under natural conditions.
\end{abstract}

Key words: Ioan area, soil degradation, green manure, organic matter 


\section{INTRODUÇÃO}

Com o aumento da população sentiu-se a necessidade de maior produção de alimentos e condições básicas de sobrevivência e, em consequência, aumento do consumo de energia. Com isto, surgiu a premência de construção de usinas hidroelétricas.

$\mathrm{Na}$ década de 60 foram iniciadas várias obras no estado de São Paulo com o intuito de cobrir a demanda. Na época não havia leis que exigissem relatórios de impactos ambientais; assim, a construção da usina hidrelétrica de Ilha Solteira, SP, acarretou alto nível de degradação no ecossistema da região e no solo de onde foi retirado o material para construção da fundação e paredes da barragem (Kitamura et al., 2008).

A geração de energia utilizando a queda d'água num curso natural é considerada energia limpa as a obra de engenharia deixa sequelas visto que grandes áreas são inundadas e enormes volumes de solo são removidos para a execução das terraplanagens e fundações, dando origem às chamadas "áreas de empréstimos".

As áreas de empréstimo se constituem de um ecossistema degradado, pois foram eliminados, juntamente com a vegetação, dos seus meios de regeneração bióticos, como o banco de sementes, banco de plântulas e rebrota. Apresenta, portanto, baixa resiliência, isto é, seu retorno ao estado anterior pode não ocorrer ou ser extremamente lento (Alves et al., 2007).

Na recuperação de uma área degradada o desafio maior é o estabelecimento do horizonte A para que, a partir daí, o condicionamento em que indicadores são muito utilizados para a avaliação e monitoramento de ecossistemas naturais; tratase de um assunto muito discutido e alguns experimentos estão sendo realizados.

Alves (1992) afirma que para a manutenção e melhoria das condições físicas internas e externas do solo, a adição e o balanço da matéria orgânica são fundamentais, haja vista que esta manutenção e melhoria só poderão ser alcançadas e mantidas via biológica, isto é, por meio de ação de raízes, da atividade macro e microbiológica e da decomposição da matéria orgânica.

Moreira (2004) afirma que a recuperação de solos degradados pode ser buscada por meio de cobertura vegetal com espécies que tenham facilidade de estabelecimento rápido, desenvolvimento de cobertura e que melhorem as condições físicas, biológicas e de fertilidade do solo e a adubação verde possa interferir em diversos atributos do solo, uma vez que a adição de matéria orgânica altera suas propriedades químicas, físicas e biológicas. A cobertura vegetal melhora o teor de matéria orgânica favorecendo a absorção de água e melhorando a estruturação do solo Baruqui \& Fernandes (1985).

Rodrigues et al. (2007) observaram, estudando a dinâmica da regeneração do solo de áreas degradadas dentro do bioma Cerrado, que as coberturas vegetais utilizadas na revegetação estão modificando seus atributos químicos e que o Pinus sp não foi uma boa espécie para recuperar esses atributos, comparados com os das áreas com espécies nativas de Cerrado, em regeneração natural ou com Brachiaria brizantha.

A relação entre massa e volume do solo, ou seja, o volume ocupado por poros e por partículas é denominado densidade do solo. A densidade do solo é variável para um mesmo tipo de solo, dependendo da estruturação e, se for manejado incorretamente, poderá provocar a compactação, alterando a estruturação.

Para reduzir o valor da densidade do solo recomenda-se a aplicação de matéria orgânica nas suas diferentes formas de adubação verde, de estercos animais, de composto preparado na fazenda, de tortas vegetais e demais resíduos industriais, como a vinhaça, o bagacinho, palha de arroz etc (Kiehl, 1979).

Estudos foram realizados para verificar a ação de lodo de esgoto na reestruturação de um solo e o efeito nas plantas de braquiária e eucalipto enquanto Campos \& Alves (2008) verificaram que o uso do lodo de esgoto exerceu efeito benéfico nas propriedades físicas (densidade do solo, porosidade total e macroporosidade) e proporcionaram maior rendimento de massas verde e seca da braquiária além de promoverem, ainda, maior crescimento das plantas de eucalipto.

Castro et al. (2009) verificaram, estudando a recuperação da estabilidade estrutural de um Latossolo Vermelho degradado tratado com adubos verdes (mucuna-preta e guandu), calcário e gesso e revegetado com $B$. decumbens, após 13 anos, avaliando a estabilidade de agregados em três profundidades, que o conteúdo de matéria orgânica e outras propriedades químicas não apresentaram qualquer relação com a estabilidade de agregados mas foi observada uma ligeira recuperação da propriedade física estudada, embora seja menor que a estabilidade do solo original.

Mediante a preocupação de equacionar os problemas que envolvem a recuperação do solo e compreender os fatores que estão associados à resiliência da área estudada, estudou-se a densidade do solo e a resistência à penetração, como indicadores da qualidade física de um Latossolo Vermelho, que está em processo de recuperação há 17 anos, tendo-se utilizado adubos verdes, gesso e pastagem.

\section{Material e MÉTODOS}

O trabalho foi realizado em Selvíria, MS, localizada nas coordenadas geográficas de $51^{\circ} 22^{\prime}$ de longitude oeste de Greenwich e $20^{\circ} 22^{\prime}$ de latitude sul, com altitude média de 327 m. A região apresenta médias de precipitação anual de 1370 $\mathrm{mm}$, temperatura de $23,5^{\circ} \mathrm{C}$ e umidade relativa do ar entre $70 \mathrm{e}$ $80 \%$.

O solo original da área de estudo foi classificado como Latossolo Vermelho-Escuro distrófico, textura média, muito profundo, rico em sesquióxidos (Alves \& Souza, 2008). Pela nomenclatura atual é um Latossolo Vermelho distrófico (EMBRAPA, 2006).

Da área em estudo foram retirados $8,6 \mathrm{~m}$ do perfil do solo original, para o uso na construção da Usina de Ilha Solteira, ficando exposto o subsolo da área em estudo, desde 1969 (Alves $\&$ Souza, 2008). No ano de 1992 o subsolo se apresentava com compactação superficial e baixa presença de vegetação espontânea. Nesse mesmo ano se iniciou o trabalho de recuperação e o preparo do solo foi realizado efetuando-se uma subsolagem atingindo profundidade média de $0,40 \mathrm{~m}$. Foi efetuada também uma aração e após essa operação uma 
gradagem niveladora. Realizaram-se a caracterização físicoquímica da área e a densidade do solo $=1,76 \mathrm{~kg} \mathrm{~m}^{-3} ; \mathrm{P}=0,5$ $\mathrm{mg} \mathrm{dm}{ }^{-3} ;$ M.O. $=5,5 \mathrm{~g} \mathrm{dm}^{-3} ; \mathrm{pH}\left(\mathrm{CaCl}_{2}\right)=4,1 ; \mathrm{K}=0,2 \mathrm{mmol}_{\mathrm{c}} \mathrm{dm}^{-3}$; $\mathrm{Ca}=2,0 \mathrm{mmol}_{\mathrm{c}} \mathrm{dm}^{-3} ; \mathrm{Mg}=1,0 \mathrm{mmol}_{\mathrm{c}} \mathrm{dm}^{-3} ; \mathrm{H}+\mathrm{Al}=20,0$ $\mathrm{mmol}_{\mathrm{c}} \mathrm{dm}^{-3} ; \mathrm{SB}=3,2 \mathrm{mmol}_{\mathrm{c}} \mathrm{dm}^{-3} ; \mathrm{CTC}=23,2 \mathrm{mmol} \mathrm{dm}_{\mathrm{c}}^{-3} \mathrm{eV} \%=14$.

A correção do solo foi baseada na caracterização química da área experimental. Com a aplicação de calcário para elevar a saturação por bases a 70\%, e no caso das parcelas com calcário e gesso, ocorreu a substituição de $25 \%$ de $\mathrm{CaO}$ do calcário por $25 \%$ do gesso, ambos incorporados ao solo.

Foram semeadas, em dezembro-janeiro dos anos de 1992 a 1996, espécies de adubo verde (mucuna-preta (Stizolobium aterrimum) Piper \& Tracy, guandu (Cajanus cajan L. Millsp) aveia-preta (Avena strigosa Schieb) e feijão-de-porco (Canavalia ensiformis (L.) DC). A semeadura das espécies foi realizada manualmente e a densidade de semeadura dos adubos verdes foi de 10 plantas $\mathrm{m}^{-1}$, com o intuito de melhorar as características físicas e químicas do subsolo em estudo, enquanto no início do florescimento eram roçadas e deixadas na superfície.

Em 1996 novamente se realizou a correção do solo com base na análise química, para os tratamentos com calcário e calcário mais gesso. A substituição de $\mathrm{Ca} \mathrm{O}$ do calcário pelo $\mathrm{CaO}$ do gesso seguiu o mesmo procedimento do início do trabalho. A correção foi efetuada nos casos em que a saturação por bases estava inferior a $60 \%$, objetivando-se elevá-la a $70 \%$.

Em janeiro de 1997 foi semeada, em toda a área experimental, a cultura do milho (Zea mays L.) utilizando-se a semente AG 405 e $250 \mathrm{~kg} \mathrm{ha}^{-1}$ da fórmula 4-30-10 mais 0,3\% de zinco, sem aplicação de calcário; em junho de 1998 foi semeada a aveiapreta (Avena strigosa Schieb.); em fevereiro de 1999 foi semeada a Brachiaria decumbens Stapf., com o intuito de proteger o solo e lhe acumular matéria orgânica; enfim, em 2006 começaram a aparecer, naturalmente, espécies arbóreas nativas de cerrado.

$\mathrm{O}$ delineamento experimental utilizado foi inteiramente casualizado constando de nove tratamentos e quatro repetições. Os dados foram comparados com duas testemunhas T1 - Solo exposto (sem técnica de recuperação) e T2 - Vegetação nativa de Cerrado. Cada parcela teve dimensão de 10 x 10 m.

Os tratamentos foram: Testemunha (solo mobilizado) até 1999, após implantado Brachiaria decumbens; Mucuna-preta (Stizolobium aterrimum Piper \& Tracy) até 1999 após substituído por B. decumbens (MP/B); Guandu (Cajanus cajan (L.) Millsp), até 1994, após substituído por Feijão-de-porco e a partir de 1999 substituído por B. decumbens (G/FP/B); calcário + mucuna-preta até 1999, após substituído por B. decumbens (C+MP/B); Calcário+Guandu até 1994, após substituído por Feijão-de-porco e a partir de 1999 substituído por B. decumbens (C + G/FP/B); calcário + gesso + mucuna-preta até 1999, após substituído por $B$. decumbens $(\mathrm{C}+\mathrm{Ge}+\mathrm{MP} / \mathrm{B})$; calcário + gesso + guandu, até 1994, após substituído por feijão-de-porco e a partir de 1999 substituído por B. decumbens $(\mathrm{C}+\mathrm{Ge}+\mathrm{G} / \mathrm{FP} / \mathrm{B})$.

Foram realizadas as avaliações físicas do solo: densidade do solo pelo método do anel volumétrico, de acordo com EMBRAPA (1997), resistência do solo à penetração utilizandose um penetrógrafo tipo Penetrographer PATSC-60 e umidade gravimétrica do solo pelo método clássico de pesagem (EMBRAPA, 1997).
Para as análises e de acordo com suas especificidades, foram coletadas amostras indeformadas de solo, com anel volumétrico em três camadas de solo: 0-0,10; 0,10-0,20 e de 0,20-0,40 m, com três amostras por parcela e nas camadas de solo de $0-0,15$; 0,15-0,30 m se avaliaram a resistência do solo à penetração (três pontos por parcela) e a umidade gravimétrica do solo (uma amostra por parcela).

Avaliou-se, também, a produção de massa seca de Brachiaria decumbens a cada três meses. Foram coletadas plantas contidas em $1,00 \mathrm{~m}^{2}$, de dois pontos de cada parcela. A massa de matéria seca foi avaliada por pesagem (estufa a 60$70{ }^{\circ} \mathrm{C}$ até atingir massa constante). Os dados foram representados em $\mathrm{kg} \mathrm{ha}^{-1}$.

Analisaram-se os dados efetuando-se a análise de variância e o teste de Tukey para as comparações de média no nível de 5 $\%$ de probabilidade. Por fim, foi usado o programa computacional SISVAR (Ferreira, 2003).

\section{RESULTADOS E DISCUSSÃO}

Analisando os dados de resistência do solo à penetração (Tabela 1) na camada de $0,00-0,15 \mathrm{~m}$, verificou-se que a maior resistência encontrada foi no solo exposto, diferindo de todos os demais tratamentos. Todos os tratamentos usados para recuperação do solo apresentaram resistência do solo à penetração semelhante à condição do solo sob vegetação de Cerrado. O tratamento $\mathrm{C}+\mathrm{MP} / \mathrm{B}$ diferiu dos tratamentos $\mathrm{C}+$ $\mathrm{Ge}+\mathrm{G} / \mathrm{FP} / \mathrm{B}$ e MP/B, apresentando maior resistência do solo à penetração.

Nascimento et al. (2004) obteve, avaliando a recuperação do solo nesta mesma área, valores semelhantes aos desta pesquisa e o tratamento $\mathrm{C}+\mathrm{Ge}+\mathrm{G} / \mathrm{FP} / \mathrm{B}$ também foi o mais

Tabela 1. Teste F, coeficiente de variação (CV), diferença mínima significativa (DMS) e valores médios de resistência do solo à penetração (M Pa) para os tratamentos estudados nas camadas de 0-0,15 e 0,15-0,30 m, no ano de 2008

\begin{tabular}{lcc}
\hline & \multicolumn{2}{c}{ Camadas do solo (m) } \\
\cline { 2 - 3 } & $\mathbf{0 - 0 , 1 5}$ & $\mathbf{0 , 1 5 - 0 , 3 0}$ \\
F & $11,05^{*}$ & $7,61^{*}$ \\
DMS-5\% & 1,074 & 1,207 \\
CV (\%) & 20,82 & 20,03 \\
\hline SM/B & $3,2 \mathrm{ABC}$ & $4,3 \mathrm{CD}$ \\
$\mathrm{MP} / \mathrm{B}$ & $2,4 \mathrm{AB}$ & $3,2 \mathrm{ABC}$ \\
$\mathrm{G} / \mathrm{FP} / \mathrm{B}$ & $3,4 \mathrm{BC}$ & $3,8 \mathrm{BCD}$ \\
$\mathrm{C}+\mathrm{MP} / \mathrm{B}$ & $3,7 \mathrm{C}$ & $4,2 \mathrm{CD}$ \\
$\mathrm{C}+\mathrm{G} / \mathrm{FP} / \mathrm{B}$ & $3,1 \mathrm{ABC}$ & $4,2 \mathrm{CD}$ \\
$\mathrm{C}+\mathrm{Ge}+\mathrm{MP} / \mathrm{B}$ & $3,0 \mathrm{ABC}$ & $3,7 \mathrm{ABC}$ \\
$\mathrm{C}+\mathrm{Ge}+\mathrm{G} / \mathrm{FP} / \mathrm{B}$ & $2,2 \mathrm{~A}$ & $2,5 \mathrm{~A}$ \\
$\mathrm{MA}$ & $3,0 \mathrm{ABC}$ & $3,0 \mathrm{AB}$ \\
$\mathrm{SE}$ & $4,9 \mathrm{D}$ & $4,9 \mathrm{D}$ \\
\hline
\end{tabular}

Médias seguidas de letras iguais na coluna não diferem entre si pelo teste de Tukey a $5 \%$ de probabilidade

SM/B - Solo mobilizado até 1999, após implantado braquiária; MP/B - Mucuna-preta até 1999 após substituído por braquiária; G/FP/B - Guandu até 1994, após substituído por feijão-de-porco e a partir de 1999, substituído por braquiária; $C+M P / B=$ calcário + mucuna-preta até 1999, após substituído por braquiária; $C+\mathrm{G} / \mathrm{FP} / \mathrm{B}=$ calcário + guandu até 1994 , após substituído por feijão-de-porco e a partir de 1999 substituído por braquiária; $C+\mathrm{Ge}+\mathrm{MP} / \mathrm{B}=$ calcário + gesso + mucuna-preta até 1999, após substituído por braquiária; $C+\mathrm{Ge}+\mathrm{G} / \mathrm{FP} / \mathrm{B}=$ calcário + gesso + guandu até 1994 , após substituído por feijão-de-porco, e a partir de 1999 substituído por braquiária; MA - vegetação nativa do cerrado; SE - solo exposto 
promissor em apresentar menor resistência do solo à penetração quando comparado com os demais tratamentos. Os tratamentos de recuperação indicam que o solo está sendo influenciado positivamente, pois a resistência do solo à penetração informa que o solo está menos compactado, no solo sob os tratamentos, quando comparado ao solo exposto.

Neiro et al. (2003) verificaram, trabalhando com Latossolo Vermelho distroférrico sob plantio direto estudando o comportamento da resistência do solo à penetração com rotação e sucessão de culturas, que os sistemas de manejo influenciaram a resistência na camada superficial e que a rotação de cultura (aveia-milho-aveia-soja-trigo) influenciou positivamente devido ao sistema radicular eficiente da aveia e do milho, comportamento semelhante ao encontrado neste trabalho, de vez que o tratamento $\mathrm{C}+\mathrm{Ge}+\mathrm{G} / \mathrm{FP} / \mathrm{B}$ que combina corretivo do solo, gesso e adubo verde com sistema radicular pivotante, obteve efeito similar.

$\mathrm{Na}$ camada de 0,15-0,30 m (Tabela 1) verificou-se que os tratamentos não estão sendo eficientes na recuperação do solo uma vez que a resistência do solo à penetração da condição de solo degradado e sem intervenção para sua recuperação (solo exposto) foi semelhante para os tratamentos SM/B; G/FP/B; C $+\mathrm{MP} / \mathrm{B}$ e $\mathrm{C}+\mathrm{G} / \mathrm{FP} / \mathrm{B}$. Por outro lado, esses mesmos tratamentos diferiram do tratamento $\mathrm{C}+\mathrm{Ge}+\mathrm{G} / \mathrm{FP} / \mathrm{B}$, que apresentou menor resistência do solo à penetração do que eles. Os tratamentos que apresentaram resistência do solo à penetração, semelhante à condição de solo sob Cerrado, foram: $\mathrm{C}+\mathrm{Ge}+\mathrm{G} / \mathrm{FP} / \mathrm{B}$; MP/ $\mathrm{B} ; \mathrm{G} / \mathrm{FP} / \mathrm{B} ; \mathrm{C}+\mathrm{Ge}+\mathrm{MP} / \mathrm{B}$.

$\mathrm{O}$ efeito do sistema radicular do feijão-de-porco agiu em profundidade e na camada de $0,15-0,30 \mathrm{~m}$ o tratamento que combinou adubo verde, calcário e gesso, mostrou este efeito. Referido comportamento evidencia que o tratamento $\mathrm{C}+\mathrm{Ge}+$ G/FP/B proporcionou uma condição química pelo desenvolvimento do adubo verde, e consequentemente, melhoria na qualidade física do solo.

Campos \& Alves (2006) estudaram resistência do solo à penetração em área degradada semelhante à desta pesquisa e a recuperação atingiu a camada de 0,00-0,05 m; este estudo mostra que o efeito da matéria orgânica tem atingido até a camada de 0,10 m. Comparando com dados obtidos na mesma área experimental em 2004 por Nascimento et al. (2004), notouse que houve redução da resistência do solo à penetração nas camadas, indicando melhoria na qualidade física do solo.

Pedrotti et al. (2001); Ralisch et al. (2008) e Castro Filho et al. (1998) estudaram a resistência do solo à penetração sob sistemas de plantio direto e verificaram redução desses valores praticamente em todas as profundidades, com o passar dos anos, fato este dependente dos benefícios que tal sistema proporciona ao solo. O acúmulo de matéria orgânica em superfície (lenta mineralização), associado à macro e microfaunas, desempenha papel significativo nas propriedades físicas do solo, melhorando-as.

Vários autores (Reichert et al., 2007; Arshad et al., 1996; Grant \& Lanfond, 1993; Ehlers et al., 1983) buscam um valor ou uma faixa de valores críticos de resistência do solo à penetração que restringem o crescimento das plantas e, ainda há incertezas quanto a esses valores, devido à diversidade de comportamento das plantas e solos.
Magalhães et al. (2001) trabalhando coma produção da Brachiaria brizanta e a evolução dos atributos físicos do solo na região de cerrado, verificaram que a produção de matéria seca foi inversamente proporcional a resistência a penetração. Neste mesmo trabalho verificou que os valores críticos para a resistência a penetração foi de $2,2 \mathrm{MPa}$, resultado muito semelhante ao encontrado por Reichert et al. (2007) que foi de 2,5 $\mathrm{MPa}$.

A determinação da umidade do solo no momento da avaliação da resistência do solo à penetração (Tabela 2) é fundamental para se realizar adequadamente a interpretação dos resultados encontrados. Nas camadas de solo estudadas ocorreu nenhuma ou pequena variação da umidade do solo entre os tratamentos, o que reforça a interpretação efetuada, de vez que as diferenças encontradas não estão sendo influenciadas pelo conteúdo de água do solo.

Tabela 2. Teste $F$, coeficiente de variação (CV), diferença mínima significativa (DMS) e val ores médios de umidade do solo $\left(\mathrm{kg} \mathrm{kg}^{-1}\right)$ para os tratamentos estudados, nas camadas de $0-0,15$ e 0,15-0,30 m, no ano de 2008

\begin{tabular}{lcc}
\hline & \multicolumn{2}{c}{ Umidade do solo $\mathbf{~ k g ~ k g ~}^{-\mathbf{1}}$ ) } \\
\cline { 2 - 3 } F & $\mathbf{0 - 0 , 1 5 ~ \mathbf { ~ }}$ & $\mathbf{0 , 1 5 - 0 , 3 0 ~} \mathbf{~}$ \\
DMS-5\% & $0,77^{\text {NS }}$ & $2,15^{*}$ \\
CV (\%) & 0,003 & 0,029 \\
\hline SM/B & 38,70 & 10,50 \\
MP/B & $0,10 \mathrm{~A}$ & $0,12 \mathrm{ABC}$ \\
G/FP/B & $0,10 \mathrm{~A}$ & $0,13 \mathrm{BC}$ \\
$\mathrm{C}+\mathrm{MP} / \mathrm{B}$ & $0,10 \mathrm{~A}$ & $0,12 \mathrm{ABC}$ \\
$\mathrm{C}+\mathrm{G} / \mathrm{FP} / \mathrm{B}$ & $0,10 \mathrm{~A}$ & $0,12 \mathrm{ABC}$ \\
$\mathrm{C}+\mathrm{Ge}+\mathrm{MP} / \mathrm{B}$ & $0,10 \mathrm{~A}$ & $0,11 \mathrm{AB}$ \\
$\mathrm{C}+\mathrm{Ge}+\mathrm{G} / \mathrm{FP} / \mathrm{B}$ & $0,10 \mathrm{~A}$ & $0,12 \mathrm{ABC}$ \\
$\mathrm{MA}$ & $0,15 \mathrm{~A}$ & $0,12 \mathrm{ABC}$ \\
SE & $0,10 \mathrm{~A}$ & $0,13 \mathrm{~A}$ \\
\hline
\end{tabular}

Médias seguidas de letras iguais na coluna não diferem entre si pelo teste de Tukey a $5 \%$ de probabilidade

SM/B - Solo mobilizado até 1999, após implantado braquiária; MP/B - Mucuna-preta até 1999 após substituído por braquiária; G/FP/B - Guandu até 1994, após substituído por feijão-de-porco e a partir de 1999, substituído por braquiária; C + MP/B = calcário + mucuna-preta até 1999, após substituído por braquiária; $C+G / F P / B=$ calcário+ guandu até 1994 , após substituído por feijão-de-porco e a partir de 1999 substituído por braquiária; $C+G e+M P / B=$ calcário + gesso + mucuna-preta até 1999, após substituído por braquiária; $C+\mathrm{Ge}+\mathrm{G} / \mathrm{FP} / \mathrm{B}=$ calcário + gesso + guandu até 1994, após substituído por feijão-de-porco, e a partir de 1999 substituído por braquiária; MA - vegetação nativa do cerrado; SE - solo expos to

Neiro et al. (2003) verificaram que a determinação de umidade do solo é de extrema importância e se determinada a resistência do solo à penetração abaixo da capacidade de campo, os valores obtidos serão maiores podendo levar a uma falsa interpretação.

Campos \& Alves (2008) estudando resistência do solo à penetração em condições semelhantes às deste trabalho, verificaram que o solo em condições naturais (cerrado) se apresentou sem limitação ao crescimento das raízes, pois a classe de resistência do solo à penetração é muito baixa $(<1,1$ $\mathrm{MPa}$ ) e valores acima de 2,5 MPa começam a restringir o pleno crescimento das raízes das plantas. Também Canarache (1990) afirma que valores 2,6-5,0 MPa se enquadram na classe média e as raízes podem sofrer algumas limitações no seu crescimento.

Para a densidade do solo (Tabela 3 ) na camada de $0-0,10 \mathrm{~m}$ somente o tratamento $\mathrm{C}+\mathrm{Ge}+\mathrm{MP} / \mathrm{B}$ diferiu estatisticamente do solo exposto e vegetação nativa do cerrado. $\mathrm{O}$ solo exposto 
diferiu de todos os tratamentos e apresentou o maior valor de densidade do solo. O solo sob vegetação natural de Cerrado comparado com o solo exposto (degradado) apresentou o menor valor de densidade do solo. Os demais tratamentos usados para recuperação do solo tiveram densidades do solo semelhante às da condição natural do solo, significando que os tratamentos estão sendo eficientes na recuperação da qualidade do solo nesta profundidade de estudo do solo.

Tabela 3. Teste $F$, coeficiente de variação $(C V)$, diferença mínima significativa (D MS) e valores médios de densidade do solo $\left(\mathrm{Mg} \mathrm{m}^{-3}\right)$ para os tratamentos estudados, nas camadas de $0-0,10 ; 0,10-0,20$ e 0,20-0,40 m, no ano de 2008

\begin{tabular}{|c|c|c|c|}
\hline & \multicolumn{3}{|c|}{ Camadas do solo (m) } \\
\hline & $0-0,10$ & $0,10-0,20$ & $0,20-0,40$ \\
\hline $\begin{array}{l}\text { F } \\
\text { CV (\%) } \\
\text { DMS - } 5 \%\end{array}$ & $\begin{array}{c}16,37^{*} \\
5,42 \\
0,1045\end{array}$ & $\begin{array}{l}1,764^{\text {ns }} \\
5,99 \\
0,1285\end{array}$ & $\begin{array}{l}6,094^{*} \\
6,34 \\
0,1437\end{array}$ \\
\hline $\begin{array}{l}\text { SM/B } \\
\text { MP/B } \\
\text { G/FP/B } \\
C+M P / B \\
C+G / F P / B \\
C+G e+M P / B \\
C+G e+G / F P / B \\
\text { SE } \\
\text { MA }\end{array}$ & $\begin{array}{l}1,45 A B \\
1,48 A B \\
1,48 A B \\
1,42 A B \\
1,46 A B \\
1,51 B \\
1,48 A B \\
1,72 C \\
1,38 A\end{array}$ & $\begin{array}{l}1,67 \mathrm{~A} \\
1,67 \mathrm{~A} \\
1,66 \mathrm{~A} \\
1,61 \mathrm{~A} \\
1,70 \mathrm{~A} \\
1,63 \mathrm{~A} \\
1,64 \mathrm{~A} \\
1,72 \mathrm{~A} \\
1,57 \mathrm{~A}\end{array}$ & $\begin{array}{l}1,74 \mathrm{BC} \\
1,73 \mathrm{BC} \\
1,78 \mathrm{BC} \\
1,77 \mathrm{BC} \\
1,76 \mathrm{BC} \\
1,81 \mathrm{BC} \\
1,70 \mathrm{AB} \\
1,86 \mathrm{C} \\
1,54 \mathrm{~A}\end{array}$ \\
\hline
\end{tabular}

Médias seguidas de letras iguais na coluna, não diferem estatisticamente entre si, pelo teste de Tukey a $5 \%$ de probabilidade.

SM/B - Solo mobilizado até 1999, após implantado braquiária; MP/B - Mucuna-preta até 1999 após substituído por braquiária; G/FP/B - Guandu até 1994, após substituído por feijão-de-porco e a partir de 1999, substituído por braquiária; C + MP/B = calcário + mucuna-preta até 1999, após substituído por braquiária; $C+$ G/FP/B = calcário + guandu até 1994, após substituído por feijão-de-porco e a partir de 1999 substituído por braquiária; $C+G e+M P / B=$ calcário + gesso + mucuna-preta até 1999 , após substituído por braquiária; $\mathrm{C}+\mathrm{Ge}+\mathrm{G} / \mathrm{FP} / \mathrm{B}=$ calcário + gesso + guandu até 1994, após substituído por feijão-de-porco, e a partir de 1999 substituído por braquiária; MA - vegetação nativa do cerrado; SE - solo exposto

Os resultados mostram que o solo degradado está recuperando suas propriedades e atingindo valores considerados bons, segundo Reichert et al. (2003) que consideram $1,55 \mathrm{~kg} \mathrm{~m}^{-3}$ densidade crítica para o bom crescimento do sistema radicular em solos de textura média. Estudos realizados por Alves \& Souza (2008) em 1998 e Nascimento et al. (2004) em 2004 nesta mesma área experimental, mostram maiores valores da densidade do solo na camada superficial. Esses resultados indicam que os tratamentos de recuperação têm contribuído para melhorar a qualidade física do solo e o sistema radicular na camada superficial, fornecendo matéria orgânica importante para a recuperação da estrutura do solo.

Na camada de 0,10-0,20 m os tratamentos de recuperação do solo e as testemunhas não diferiram estatisticamente entre si. Comparando com os dados encontrados por Nascimento et al. (2004) constatou-se redução na densidade do solo nesta camada, sinal de que as raízes da braquiária fornecem matéria orgânica para o solo e, com o passar do tempo, este efeito está atingindo camadas mais profundas.

Resultados semelhantes foram encontrados por Canarache (1990) estudando o efeito da adição de matéria orgânica na recuperação de solo degradado. A adição da matéria orgânica por meio dos adubos verdes e do sistema radicular da braquiária proporciona efeito positivo sobre as propriedades físicas do solo. Também Bonini et al. (2008a) verificaram que a adição de matéria orgânica na recuperação do solo degradado diminui a densidade do solo, concordando com os dados obtidos neste trabalho.

Para a camada de $0,20-0,40 \mathrm{~m}$ somente o tratamento $\mathrm{C}+\mathrm{Ge}+$ G/FP/B apresentou densidade do solo semelhante à da condição de solo sob vegetação natural de Cerrado porém diferiu apenas do solo exposto (degradado), ao contrário dos demais tratamentos. O solo exposto apresentou o maior valor de densidade do solo reforçando a condição de solo com forte grau de degradação. Nesta camada se observou, portanto, que o tratamento $\mathrm{C}+\mathrm{Ge}+\mathrm{G} / \mathrm{FP} / \mathrm{B}$ é o que está se mostra mais promissor na recuperação da qualidade física do solo.

A adição de matéria orgânica do solo influencia vários atributos fisicos-hidricos do solo como: estabilidade de agregados, infiltração, resistência a penetração e porosidade do solo. O oposto é a degradação do solo que resulta em um solo compactado (perda da estrutura e baixo teor de matéria orgânica).

Neste trabalho verificaram que a adição de matéria orgânica principalmente pelo aporte advindo das raízes de Braquiaria decumbens foram fundamental na recuperação dos atributos físicos estudados. Com o incremento houve redução da densidade do solo e resistência a penetração, aumento da estabilidade de agregados (Bonini \& Alves, 2011). Também foi verificado por Campos et al. (2011) e Colodro et al. (2010) melhorias na qualidade físico-hidricas do solo em área experimental semelhante.

Para a produção de massa seca da braquiária (Tabela 4) notou-se, para o tratamento e época, que houve significância e, para a interação tratamento x época, não ocorreu significância.

Comparando os tratamentos de recuperação conclui-se que os tratamentos $\mathrm{C}+\mathrm{Ge}+\mathrm{G} / \mathrm{FP} / \mathrm{B}$ e o $\mathrm{C}+\mathrm{Ge}+\mathrm{MP} / \mathrm{B}$ tiveram, respectivamente, menor e maior produção de massa seca da $B$. decumbens e o tratamento $\mathrm{C}+\mathrm{Ge}+\mathrm{MP} / \mathrm{B}$ diferiu estatisticamente do tratamento $\mathrm{C}+\mathrm{Ge}+\mathrm{G} / \mathrm{FP} / \mathrm{B}$, mas entre os tratamentos não houve diferença para a produção de massa seca.

Comparando os tratamentos de recuperação, o C + Ge $+\mathrm{G} /$ $\mathrm{FP} / \mathrm{B}$ e o $\mathrm{C}+\mathrm{Ge}+\mathrm{MP} / \mathrm{B}$ tiveram, respectivamente, menor e maior produção de massa seca da $B$. decumbens e o tratamento $\mathrm{C}+\mathrm{Ge}+\mathrm{MP} / \mathrm{B}$ diferiu estatisticamente do tratamento $\mathrm{C}+\mathrm{Ge}+\mathrm{G}$ /FP/B, mas entre os tratamentos não houve diferença para a produção de massa seca. Já Alves \& Souza (2011) obteve, trabalhando nesta mesma área, maiores produções para o tratamento $\mathrm{C}+\mathrm{Ge}+\mathrm{G} / \mathrm{FP} / \mathrm{B}$; resultados contrastantes foram encontrados neste trabalho. A produção de massa seca de $B$. decumbens mostra que este solo está sendo recuperado, com produções iguais ou superiores às encontradas por Fernandes et al. (2008) que verificaram produções entre 1.818 e 2.439 $\mathrm{kg} \mathrm{ha}^{-1}$, em Latossolo Vermelho-Escuro.

Analisando a produção de massa seca nas diferentes épocas de coleta (Tabela 5), notou-se que na $1^{\mathrm{a}}$ época de corte o tratamento $\mathrm{C}+\mathrm{Ge}+\mathrm{G} / \mathrm{FP} / \mathrm{B}$ não indicou significância quando comparado com os tratamentos $\mathrm{C}+\mathrm{G} / \mathrm{FP} / \mathrm{B}, \mathrm{G} / \mathrm{FP} / \mathrm{B}$ e $\mathrm{C}+\mathrm{Ge}+$ MP/B.

Já na $2^{\mathrm{a}}$ época não diferiu do tratamento $\mathrm{C}+\mathrm{Ge}+\mathrm{MP} / \mathrm{B}$ significando que no período de chuvas esses tratamentos se 
Tabela 4. Valores de F, diferença mínima significativa (DMS), coeficiente de variação (CV) e valores médios de massa seca da Brachiaria decumbens (kg ha-1) nos tratamentos estudados e épocas de avaliação

\begin{tabular}{|c|c|}
\hline Causas de variação & Valor de F \\
\hline $\begin{array}{l}\text { Tratamento } \\
\text { Época } \\
\text { Tratamento x Época } \\
\text { CV - \%- }\end{array}$ & $\begin{array}{l}2,32^{*} \\
7,628^{*} \\
0,41^{\text {ns }} \\
33,78 \\
\end{array}$ \\
\hline Tratamentos & Produção de massa seca \\
\hline $\begin{array}{l}S M / B \\
M P / B \\
G / F P / B \\
C+M P / B \\
C+G / F P / B \\
C+G e+M P / B \\
C+G e+G / F P / B\end{array}$ & $\begin{array}{l}2.505 \mathrm{AB} \\
3.077 \mathrm{AB} \\
3.096 \mathrm{AB} \\
3.148 \mathrm{AB} \\
3.114 \mathrm{AB} \\
3.522 \mathrm{~B} \\
2.435 \mathrm{~A}\end{array}$ \\
\hline DMS-5\% & $1.077,3409$ \\
\hline Época & Produção de massa seca \\
\hline $\begin{array}{l}\text { J aneiro } \\
\text { Abril } \\
\text { J ulho } \\
\text { Outubro }\end{array}$ & $\begin{array}{l}2.917 \mathrm{~A} \\
2.858 \mathrm{~A} \\
3.712 \mathrm{~B} \\
2.454 \mathrm{~A} \\
\end{array}$ \\
\hline DMS-5\% & 706,7073 \\
\hline \multicolumn{2}{|c|}{ 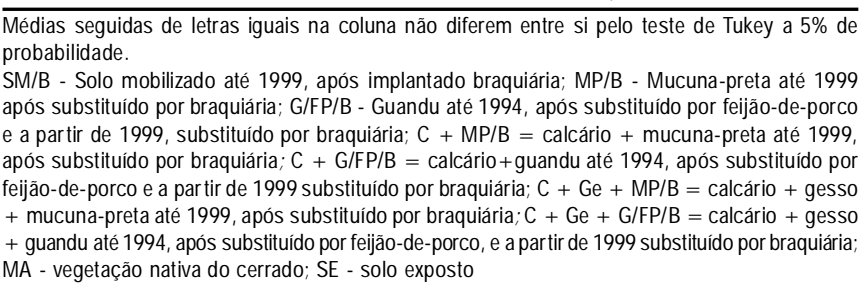 } \\
\hline
\end{tabular}

Tabela 5. Valores médios para a massa seca da Brachiaria decumbens $\left(\mathrm{kg} \mathrm{ha}^{-1}\right)$ nos tratamentos estudados nas 4 épocas de coleta

\begin{tabular}{lcccc}
\hline \multirow{2}{*}{ Tratamento } & \multicolumn{4}{c}{ Época } \\
\cline { 2 - 5 } & Janeiro & Abril & Julho & Outubro \\
SM/B & 2432,50 & 1877,07 & 3571,95 & 2138,75 \\
MP/B & 3507,50 & 2711,20 & 3538,70 & 2551,25 \\
G/FP/B & 3088,75 & 2778,32 & 4020,70 & 2495,00 \\
C+MP/B & 2770,00 & 3531,70 & 3452,57 & 2838,75 \\
C+ G/FP/B & 3163,75 & 2863,57 & 4093,45 & 2338,75 \\
C+ Ge+ MP/B & 3213,75 & 3792,45 & 4237,20 & 2845,00 \\
C+Ge+G/FP/B & 2245,00 & 2455,45 & 3069,95 & 1970,00 \\
\hline
\end{tabular}

SM/B - Solo mobilizado até 1999, após implantado braquiária; MP/B - Mucuna-preta até 1999 após substituído por braquiária; G/FP/B - Guandu até 1994, após substituído por feijão-de-porco e a partir de 1999, substituído por braquiária; C + MP/B = calcário + mucuna-preta até 1999, após substituído por braquiária; $C+\mathrm{G} / \mathrm{FP} / \mathrm{B}=$ calcário+ guandu até 1994 , após substituído por feijão-de-porco e a partir de 1999 substituído por braquiária; $C+G e+M P / B=$ calcário + gesso + mucuna-preta até 1999, após substituído por braquiária; $C+G e+G / F P / B=$ calcário + gesso + guandu até 1994, após substituído por feijão-de-porco, e a partir de 1999 substituído por braquiária; MA - vegetação nativa do cerrado; SE - solo exposto

equivalem, quanto à produção de massa seca da braquiária. Devido, provavelmente, ao volume de água fornecido em janeiro, as plantas de braquiária de todos os tratamentos foram bem abastecidas de água, não se diferenciando, portanto, entre si. Resultados semelhantes foram observados por Bonini et al. (2008b). Ressalta-se que os tratamentos G/FP/B e C+G/FP/B foram diferentes e que o segundo produziu mais massa seca.

Com relação ao tratamento com mucuna-preta nas $1^{\mathrm{a}}$ e $2^{\mathrm{a}}$ épocas, quando não houve limitação de água e fotoperíodo, os tratamentos em sua combinação foram os que se destacaram na produção de massa seca de braquiária (Tabela 5). O tratamento com MP e o uso de gesso + calcário produziram mais massa seca.

A produção de fitomassa está relaciona intimamente com a qualidade físico-química do solo. Estudos realizados por Magalhães et al. (2001) mostram que a relação da produtividade é inversamente proporcional aos atributos físicos do solo (densidade do solo e resistência a penetração) e proporcional ao diâmetro médio ponderado (que representa a estabilidade de agregados do solo). Em relação aos atributos químicos do solo Moreira et al. (2005) verificaram relação proporcional entre a produtividade da matéria seca com $\mathrm{pH}, \mathrm{Ca}^{+2}, \mathrm{Mg}^{+2}, \mathrm{P}, \mathrm{K}^{+}, \mathrm{Zn}$ e matéria orgânica do solo. Essa relação estudada pelos autores também foi verificada neste estudo.

Em áreas degradadas a produção da matéria seca é resultado da diminuição do volume de raízes e pela maior concentração do sistema radicular na camada superficial (Müller et al., 2001). Esse comportamento é causado pela perda da qualidade física do solo, com a compactação há uma redução dos macroporos, diminui a quantidade de água disponível para a planta e consequentemente diminui a produção de matéria seca.

\section{CONCLusões}

1. Os tratamentos utilizados para a recuperação do solo estão sendo eficientes na melhoria da qualidade do solo.

2. O tratamento em que foram usados os adubos verdes guandu/feijão-de-porco e braquiária com calagem e gesso, tem sido o melhor para a recuperação da qualidade física do solo.

3. O tratamento com adubos verdes guandu/feijão-de-porco e braquiária com calagem e gesso, proporcionou menor resistência do solo à penetração e menor densidade do solo nas camadas de solo estudadas.

4. A produção de massa seca da $B$. decumbens foi semelhante entre os tratamentos com diferentes adubos verdes, no período das águas, porém para o mesmo adubo verde a adição de calcário e/ou calcário+gesso aumentou a produção na época das secas.

5. A recuperação da qualidade física do solo está ocorrendo de forma mais significativa, até a profundidade de $0,10 \mathrm{~m}$ no solo.

\section{Agradecimentos}

À FAPESP, pelo apoio financeiro.

\section{LITERATURA CITADA}

Alves, M. C. Cultura do algodão, soja, milho e feijão em sucessão com quatro adubos verdes em dois sistemas de semeadura. Piracicaba: ESALQ/USP, 1992. 173p. Tese Doutorado

Alves, M. C.; Souza, Z. M. Recuperação de área degradada por construção de hidroelétrica com adubação verde e corretivo. Revista Brasileira de Ciência do Solo, v.32, p.2505-2516, 2008. 
Alves, M. C.; Souza, Z. M. Recuperação do subsolo em área de empréstimo usada para construção de hidrelétrica. Revista Ciência Agronômica, v.42, p.301-309, 2011.

Alves, M. C.; Suzuki, L. G. A. S.; Suzuki, L. E. A. S. Densidade do solo e infiltração de água como indicadores da qualidade física de um Latossolo Vermelho distrófico em recuperação. Revista Brasileira de Ciência do Solo, v.31, p.617-625, 2007.

Arshad, M. A.; Lowery, B.; Grossman, B. Physical tests for monitoring soil quality. In: Doran, J. W.: Jones, A. J. (Ed.). Methods for assessing soil quality. Madison, Soil Science Society of America. 1996. p.123-141. SSSA Special publication 49

Baruqui, A. M.; Fernandes, M. R. Práticas de conservação do solo. Informe Agropecuário, v.11, p.55-68. 1985.

Bonini, C. S. B.; Alves, M. C. Estabilidade de agregados de um Latossolo Vermelho em recuperação com adubos verdes, calcário e gesso. Revista Brasileira de Ciência do Solo, v.35, p.1263-1270, 2011.

Bonini, C. S. B.; Alves, M. C.; Oliveira, B. A. Influencia de la materia organica en la densidad del suelo en Ferralsol decapitado tratado con lodo de depuradora y fertilización mineral. In: Congreso Argentino de la Ciencia del Suelo, 21, 2008, Potrero de los Funes. Anais... Potrero de Los Funes: AACS, 2008a. p.1-6.

Bonini, C. S. B.; Oliveira, B. A.; Alves, M. C. Avaliação do crescimento de plantas de eucalipto (Eucalyptus Citriodora Hook) e fitomassa de braquiária (Brachiaria decumbens) em Latossolo Vermelho tratado com lodo de esgoto e adubação mineral. In: Simpósio Nacional Sobre Recuperação de Áreas Degradadas, 7, 2008, Curitiba. Anais... Curitiba: FUPEF, 2008b. p.470-471.

Campos, F. S.; Alves, M. C. Resistência à penetração de um solo em recuperação sob sistemas agrosilvopastoris. Revista Brasileira de Engenharia Agrícola Ambiental, v.10, p.759764. 2006.

Campos, F. S.; Alves, M. C. Uso de lodo de esgoto na reestruturação de solo degradado. Revista Brasileira de Ciência do Solo, v.32, p.1389-1397, 2008.

Campos, F. S.; Alves, M. C.; Souza, Z. M.; Pereira, G. T. Atributos físico-hídricos de um Latossolo após a aplicação de lodo de esgoto em área degradada do Cerrado. Ciência Rural, v.41, p.796-803, 2011.

Canarache, A. Penetr - A generalized semi-empirical model estimating soil resistance to penetration. Soil Tillage Research, v.16, p.51-70. 1990.

Castro Filho, C.; Muzilli, O.; Padanoschi, A. L. Estabilidade dos agregados e sua relação com o teor de carbono orgânico num Latossolo Roxo distrófico, em função de sistemas de plantio, rotações de culturas e métodos de preparo das amostras. Revista Brasileira de Ciência do Solo, v.22, p.527538, 1998.

Castro, M. M. T.; Alves, M. C.; do Nascimento, V.; Castro, M. T. T. Revegetation on a removed topsoil: Effect on aggregate stability. Communications in Soil Science and Plant Analysis, v.40, p.771-786, 2009.
Colodro, G.; Alves, M. C.; Espínola, C. R.; Maia, G A.; Silva, N. F.; Souza, J. G. Recuperação de propriedades físicas de um solo degradado usando lodo de esgoto. Cultura Agronômica (UNESP. Ilha Solteira), v.19, p.67-75, 2010.Ehlers, W.; Köpke, F.; Hesse, F.; Böhm, W. Penetration resistance and root growth of oats in tilled and untilled loess soil. Soil Tillage Research, v.3, p.261-275, 1983.

Ehlers, W. W.; Kopke, F.; Hesse, F.; Bohm, W. Penetration resistance and growth of root of oats in tilled and untilled loess soil. Soil and Tillage Research, v.3, p.261-275, 1983.

EMBRAPA - Empresa Brasileira de Pesquisa Agropecuária. Ministério da Agricultura, Pecuária e Abastecimento. Manual de métodos de análise de solo. 2.ed. Rio de Janeiro: Embrapa CNPSO, 1997.212p.

EMBRAPA - Empresa Brasileira de Pesquisa Agropecuária. Ministério da Agricultura, Pecuária e Abastecimento. Sistema Brasileiro de Classificação de Solos. 2.ed. Rio de Janeiro: Embrapa CNPSO, 2006.306p.

Fernandes, F. M.; Prado, R. M.; Kawatoko, M.; Isepon, O. J. Efeito residual de calcário, nitrogênio e zinco na produção de matéria seca de Brachiária decumbens em condições de campo. Zootecnia Tropical, v.26, p.125-131, 2008.

Ferreira, D. F. Sisvar versão 5.1. DEX/UFLA, 2003. http:// www.dex.ufla.br/ danielff/softwares.htm. 10 de março de 2010.

Grant, C. A.; Lanfond, G. P. The effects of tillage systems and crop sequences on soil bulk density and penetration resistence on a clay soil in southern Saskatchewan. Canadian Journal of Soil Science, v.73, p.223-232, 1993.

Kiehl, E. J. Manual de edafologia. 1.ed. São Paulo: Ceres, 1979. $264 p$.

Kitamura, A. E.; Alves, M. C.; Suzuki, L. G. A. S.; Gonzalez, A. P. Recuperação de um solo degradado com a aplicação de adubos verdes e lodo de esgoto. Revista Brasileira de Ciência do Solo, v.32, p.405-416, 2008.

Magalhães, R. T.; Kliemann, H. J.; Oliveira, I. P. de. Evolução das propriedades físicas de solos submetidos ao manejo do sistema barreirão. Pesquisa Agropecuária Tropical, v.31, p.7-13, 2001.

Moreira, J. A. A.; Oliveira, I. P. de; Guimarães, C. M.; Stone, L. F. Atributos químicos e físicos de um Latossolo Vermelho distrófico sob pastagens recuperada e degradada. Pesquisa Agropecuária Tropical, v.35, p.155-161, 2005.

Moreira, P. R. Manejo do solo e recomposição da vegetação com vistas a recuperação de áreas degradadas pela extração de bauxita. Poços de Caldas: UNESP, 2004. 155p. Tese Doutorado

Muller, M. M. L.; Guimarães, M. de F.; Desjardins, T.; Martins, F. da S. Degradação das pastagens na Região Amazônica: Propriedades físicas do solo e crescimento das raízes. 2001.

Nascimento, V.; Andrade Júnior, R. T.; Alves, M. C. Propriedades físicas de um solo em recuperação na região do cerrado Brasileiro. In: Congreso Argentino de la Ciencia del Suelo, 19, 2004, Entre Rios. Anais... Entre Rios: Asociación Argentina de la Ciencia del Suelo, 2004. CD Rom

Neiro, E. S.; Mata, J. D. V.; Tormena, C. A.; Gonçalves, A. C. A.; Pintro, J. C.; Costa, J. M. Resistência à penetração de um Latossolo Vermelho distroférrico, com rotação e sucessão de culturas, sob plantio direto. Acta Scientiarum Agronomy, v.25, p.19-25, 2003. 
Pedrotti, A.; Pauletto, E. A; Crestana, S.; Ferreira, M. M.; Dias Júnior, M. S.; Gomes, A. S.; Turatti, A. L. Resistência mecânica à penetração de um Planossolo submetido a diferentes sistemas de cultivo. Revista Brasileira de Ciência do Solo, v.25, p.521-529, 2001.

Ralisch, R.; Miranda, T. M.; Okumura, R. S.; Barbosa, G. M. C.; Guimarães, M. G.; Scopel, E.; Balbino, L. C. Resistência à penetração de um Latossolo Vermelho Amarelo do Cerrado sob diferentes sistemas de manejo. Revista Brasileira de Engenharia Agrícola Ambiental, v.12, p.381$384,2008$.
Reichert, J. M.; Reinert, D. J.; Braida, J. A. Qualidade do solo e sustentabilidade de sistemas agrícolas. Revista Ciência Ambiental, v.27, p.29-48, 2003.

Reichert, J. M.; Suzuki, L. E. A. S.; Reinert, D. J. Compactação do solo em sistemas agropecuários e florestais: Identificação, efeitos, limites críticos e mitigação. In: Ceretta, C. A.; Silva, L. S.; Reichert, J. M. Tópicos em ciência do solo. Sociedade Brasileira de Ciência do Solo, p.49-134, 2007.

Rodrigues, B. R.; Maltoni, K. L.; Cassiolato, A. M. R. Dinâmica da regeneração do subsolo de áreas degradadas dentro do bioma cerrado. Revista Brasileira de Engenharia Agrícola e Ambiental, v.11, p.73-80, 2007. 